\title{
Laparoscopic incisional hernia repair is feasible and safe after liver transplantation
}

\author{
Anita Kurmann • Guido Beldi - Stephan A. Vorburger • \\ Christian A. Seiler • Daniel Candinas
}

Received: 2 May 2009/ Accepted: 11 November 2009/Published online: 29 December 2009

(C) Springer Science+Business Media, LLC 2009

\begin{abstract}
Background Incisional hernia is a common complication after liver transplantation. The current study evaluated incidence and risk factors for incisional hernia and compared laparoscopic and open hernia repair in terms of feasibility and outcome.

Methods A cohort of 225 patients was prospectively investigated. The median follow-up period was 61 months (range, 6-186 months). The study cohort had 31 patients who underwent open repair and 13 who underwent laparoscopic repair.

Results Incisional hernia, found in 57 patients (25\%), had occurred after a median of 17 months (range, 5138 months). The significant risk factors were male gender $(p=0.001)$ and body mass index (BMI) greater than $25 \mathrm{~kg} /$ $\mathrm{m}^{2}(p=0.002)$. A trend toward a lower recurrence rate (15\% vs $35 \% ; p=0.28)$ and fewer surgical complications (15\% vs $19 \%$; $p=0.99$ ) was found in the laparoscopic group.

Conclusions Incisional hernia is a frequent complication after liver transplantation. Associated risk factors are male gender and a BMI greater than $25 \mathrm{~kg} / \mathrm{m}^{2}$. Laparoscopic hernia repair for such patients is feasible and safe.
\end{abstract}

Keywords Incidence · Incisional hernia . Laparoscopic surgery · Liver transplantation . Open surgery $\cdot$ Risk factors

A. Kurmann · G. Beldi $(\square) \cdot$ S. A. Vorburger

C. A. Seiler · D. Candinas

Department of Visceral Surgery and Medicine,

Inselspital University Hospital Bern and University Bern,

CH-3010 Bern, Switzerland

e-mail: guido.beldi@insel.ch
Incisional hernia is a potential long-term complication after liver transplantation. The reported incidence of incisional hernia after liver transplantation varies from 5 to $23 \%$ [16]. The risk factors for incisional hernia formation after liver transplantation, described in various reports, include advanced age, male gender, obesity, use of steroids, wound infection, incision type, and reoperation [1, 2, 4-6]. Most of the reported studies, however, were performed retrospectively.

With the introduction of modern two-layered mesh, laparoscopic incisional hernia repair has become an accepted therapeutic option leading to fewer surgery-site infections, shorter hospital stay, and lower costs for patients who have not undergone transplantation than for patients who undergo open hernia repair [7-9].

This study aimed to evaluate prospectively the incidence and risk factors of incisional hernia after liver transplantation and to determine the feasibility and safety of laparoscopic incisional hernia repair.

\section{Patients and methods}

A prospective cohort of 225 patients who had undergone 233 consecutive liver transplantations at our institution between 1993 and 2007 were investigated. Patient data were prospectively collected over a 15-year period and kept in a database. The median follow up period was 61 months (range, 6-186 months). Most of the patients (95\%) underwent clinical and laboratory follow-up investigations performed by a transplantation hepatologist at least once a year at our institution. Suspicious clinical findings were referred to an abdominal surgeon.

Incisional hernia was diagnosed by physical examination. A total of 57 patients with incisional hernia after liver 
transplantation were identified, and 44 of these patients underwent incisional hernia repair.

The exclusion criteria for hernia repair were medical comorbidities or a patient unwilling to undergo surgery. We compared 31 patients who underwent open incisional hernia repair with 13 patients who underwent laparoscopic hernia repair between 1994 and 2008. The patients treated before July 2004 underwent open hernia repair, whereas those treated after July 2004 underwent laparoscopic hernia repair. Thus, the follow-up period for the laparoscopic hernia repair group was shorter than for the open group.

Liver transplantation was performed using a transverse upper laparotomy with or without cranial midline extension. For all the patients, abdominal closure was performed using a two-layer running suture (polydioxanone 1 monofilament). For $90 \%$ of the patients, standard immunosuppression using a combination of calcineurin inhibitors, antimetabolites, and steroids was used. In cases of major renal failure, patients were given a combination of antimetabolites and steroids only. Postoperatively, the steroid dose was reduced to zero over a period of 4 months. No patient was held on long-term steroid therapy.

For open hernia repair, a preperitoneal polypropylene mesh was implanted in 25 patients. For six patients, the hernia was closed without mesh.

For laparoscopic hernia repair, we performed the same technique as described previously [7]. Briefly, an optic trocar was inserted using a limited open technique. A minimum of two additional trocars were inserted under direct vision. Complete adhesiolysis of the abdominal wall was performed. A dual-layer composite mesh (Parietenecomposite; Tyco Healthcare, Mansfield, MA, USA) was used for all patients. The size of the mesh was chosen to overlap the fascial defect at least $4 \mathrm{~cm}$. Nonabsorbable transfascial sutures were used caudal and lateral to the hernia every $4 \mathrm{~cm}$. Titanium tackers were applied between the sutures and cranial to the hernia into the diaphragm, avoiding puncture of the pericardium.

The main outcome measure was total morbidity after laparoscopic and open incisional hernia repair for patients who had undergone previous liver transplantation. The secondary outcome measures were incidence and risk factors of incisional hernia, operative time, rate of conversion, duration of hospital stay, and recurrence rate.

\section{Statistical analysis}

Results are expressed as median and range. Student's $t$-test was used to determine the significance between continuous variables, and Fisher's exact test was performed to compare proportions. The log-rank test was performed for univariate testing. All $p$ values less than 0.05 represent statistical significance (NCSS 2004 for Windows; NCSS, Kaysville, UT, USA).

\section{Results}

Incisional hernia was diagnosed for 57 (25\%) of the 225 patients after liver transplantation. The hernia occurred after a median of 17 months (range, 5-138 months) (Fig. 1). The significant risk factors for hernia formation were male gender $(p=0.001)$ (Fig. $2 \mathrm{~A})$ and a body mass index (BMI) greater than $25 \mathrm{~kg} / \mathrm{m}^{2}(p=0.002)$ (Fig. 2B). In the univariate analysis, age exceeding 50 years, a MELD (model for end-stage liver disease) score higher than 20, diabetes, preexisting coronary heart disease, chronic obstructive pulmonary disease, and midline extension to transverse laparotomy were not found to be significant risk factors (Table 1).

A total of 44 patients underwent surgical hernia repair. The demographic parameters were similar in the open and laparoscopic groups, as outlined in Table 2. Ascites was present in two patients $(4.5 \%)$ during open hernia repair. Multiple hernial orifices were found in 13 patients (33\%) (Table 3). The most common site for incisional hernia was at the junction of the transverse and upper midline incisions (48\%) (Table 3).

The operative time for open surgery tended to be longer than for laparoscopic surgery, but the difference was not significant (Table 4). Laparoscopy was converted to open surgery for two patients $(15 \%)$. No statistical difference was found in the median hospital stay or recurrence rate. Two surgical complications occurred in the laparoscopic group and five surgical complications in the open group (Table 4).

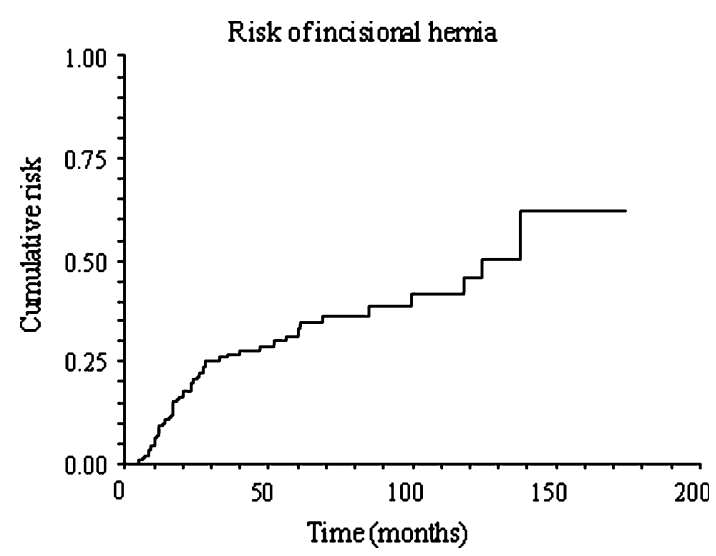

Fig. 1 Kaplan-Meier curve of cumulative risk for incisional hernia after liver transplantation 


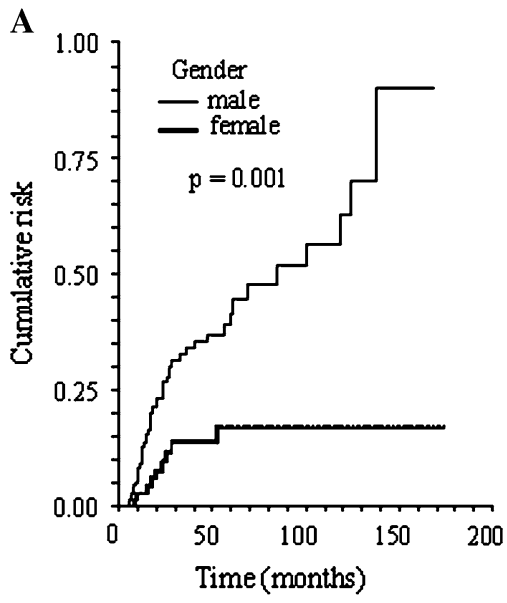

B

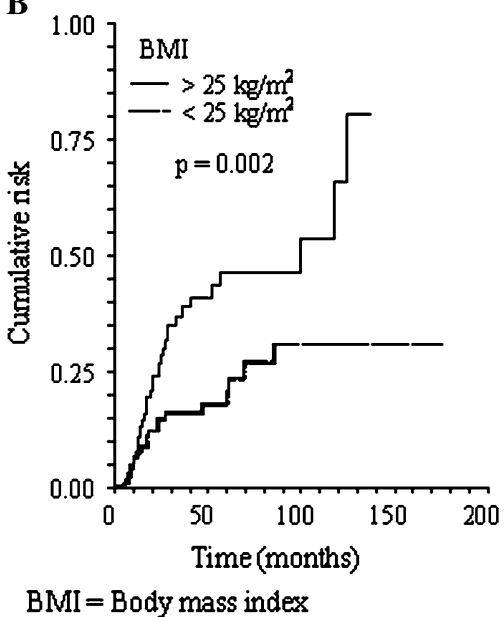

$\mathrm{BMI}=$ Body mass index

Fig. 2 Kaplan-Meier curve of significant risk factors for incisional hernia after liver transplantation. A Gender, B Body mass index

Table 1 Risk factors for incisional hernia after liver transplantation

\begin{tabular}{lll}
\hline & Hazard ratio (95\% CI) & $p$ Value \\
\hline Male gender & $3.08(1.80-5.28)$ & 0.001 \\
Age exceeding 50 years & $1.17(0.69-1.99)$ & 0.56 \\
BMI $>25 \mathrm{~kg} / \mathrm{m}^{2}$ & $2.28(1.35-3.84)$ & 0.002 \\
MELD score $>20$ & $0.69(0.37-1.27)$ & 0.28 \\
Diabetes & $1.23(0.59-2.57)$ & 0.54 \\
Coronary heart disease & $1.42(0.7-2.89)$ & 0.28 \\
COPD & $1.80(0.77-4.18)$ & 0.08 \\
Laparotomy with midline & $1.50(0.88-2.57)$ & 0.14 \\
$\quad$ extension & & \\
\hline
\end{tabular}

$C I$ confidence interval, $B M I$ body mass index, $M E L D$ model for endstage liver disease, $C O P D$ chronic obstructive pulmonary disease

${ }^{\text {a }}$ Log-rank test

\section{Discussion}

In this prospective study, the incidence of incisional hernia among patients undergoing liver transplantation was $25 \%$, observed after a median follow-up period of 17 months. Evaluation of the therapeutic approach showed that laparoscopic incisional hernia repair is safe for patients after liver transplantation and can be performed with results the same as for patients who did not undergo transplantation [10].

The $25 \%$ incidence of incisional hernia after liver transplantation, as assessed in our prospective study, is higher than for patients after abdominal surgery with no immunosuppression, as already shown in retrospective series $[1-3,5,6]$. Repetitive and long-term follow-up assessment of these high-risk patients partially explains such a high incidence. However, chronic immunosuppression, particularly newer rapamycin-based regimens, has an additional impact on wound healing and remodeling. A recent report showed a 34\% incidence of incisional hernia (during a 49-month follow-up period) after liver transplantation among patients receiving sirolimus-based immunosuppression [11].

Significant risk factors for the development of incisional hernia in our series were male gender and obesity (BMI $>25 \mathrm{~kg} / \mathrm{m}^{2}$ ), as also shown in different populations with other underlying diseases [12, 13]. Other studies showed cranial midline extension of the transverse laparotomy as a risk factor for incisional hernia [2, 4]. As a consequence of previous results, the surgical approach for liver transplantation at our institution since 2003 is transverse laparotomy without midline extension.

In the current series, we show that laparoscopic hernia repair after liver transplantation is feasible, safe, and not associated with greater morbidity than open surgery. Shortterm complications were found in our series less often after laparoscopic surgery, but this difference was not statistically significant. No long-term complications occurred. These results are comparable with those obtained in a nontransplantation population showing a lower complication rate in the laparoscopic group [10].

Similar to patients not undergoing transplantation [9], the operative time for laparoscopic hernia repair patients is not significantly longer than for the open group. As a result of extensive adhesions in two patients, the conversion rate in the laparoscopic group was $15 \%$. Series with a greater number of patients who have not undergone liver transplantation show a conversion rate of 5\% [7, 9]. The median hospital stay was shorter in the laparoscopic group than in the open group.

The recurrence rate was 34\% after open repair and 15\% after laparoscopic repair, which is higher than in other groups (Table 5) [14, 15]. The reasons that might account for this observation are intensive follow-up assessment and immunosuppression. Gomez et al. [1] described an incidence of ascites after liver transplantation as high as $20 \%$, but no association between postoperative ascites and hernia 
Table 2 Patients' demographic parameters
$B M I$ body mass index, $M E L D$ model for end-stage liver disease

${ }^{\text {a }}$ Fisher's exact test unless indicated otherwise

b Student's $t$-test

\begin{tabular}{llll}
\hline & $\begin{array}{l}\text { Open group } \\
(n=31) \\
n(\%)\end{array}$ & $\begin{array}{l}\text { Laparoscopic group } \\
(n=13) \\
n(\%)\end{array}$ & $p$ value $^{\mathrm{a}}$ \\
\hline Age: years (range) & $52(35-67)$ & $56(33-71)$ & $0.25^{\mathrm{b}}$ \\
Gender: M/F & $27 / 4$ & $10 / 3$ & 0.40 \\
BMI: $\mathrm{kg} / \mathrm{m}^{2}$ (range) & $26.9(20.9-34.8)$ & $29(19.8-36.4)$ & $0.31^{\mathrm{b}}$ \\
Liver disease & & & \\
Alcoholic & $5(16)$ & $1(8)$ & 0.65 \\
Hepatitis B, C & $7(23)$ & $6(46)$ & 0.16 \\
Tumor & $1(3)$ & $2(15)$ & 0.20 \\
Other & $18(58)$ & $4(31)$ & 0.12 \\
MELD score: (range) & $16(6-29)$ & $11(7-26)$ & $0.07^{\mathrm{b}}$ \\
Relaparotomy & $6(19.4)$ & $2(15.4)$ & 0.15 \\
Retransplantation & $1(3)$ & $1(8)$ & 0.51 \\
Exitus letalis & $6(19)$ & - & 0.16 \\
Follow-up: months (range) & $56(10-157)$ & $29(6-47)$ & $0.003^{\mathrm{b}}$ \\
\hline
\end{tabular}

Table 3 Characteristics and locations of incisional hernia

\begin{tabular}{lcll}
\hline & $\begin{array}{l}\text { Open group } \\
(n=31) \\
n(\%)\end{array}$ & $\begin{array}{l}\text { Laparoscopic } \\
\text { group }(n=13) \\
n(\%)\end{array}$ & $p$ Value $^{\mathrm{a}}$ \\
\hline $\begin{array}{l}\text { Hernial orifice } \\
\text { Single }\end{array}$ & $17(68)$ & $8(61)$ & 1.00 \\
Multiple & $8(32)$ & $5(39)$ & 0.71 \\
Location & & & \\
Right subcostal & $11(33)$ & $6(29)$ & 1.00 \\
Left subcostal & $5(15)$ & $6(29)$ & 0.13 \\
Midline & $17(52)$ & $9(43)$ & 1.00 \\
\hline
\end{tabular}

${ }^{a}$ Fisher's exact test recurrence was observed. In our series, two patients with open incisional hernia repair experienced posttransplantation ascites. Recurrent hernia was observed in one of these patients. No ascites was found during laparoscopic hernia repair.

In conclusion, laparoscopic incisional hernia repair for patients after liver transplantation proved to be safe and resulted in a trend of a shorter hospital stay, a lower recurrence rate, and fewer complications, which is similar to the results for patients who have not undergone liver transplantation [7-9, 16]. The advances in laparoscopic surgery are likely to be present in a transplanted population, so we expect these patients to show similar advances in larger studies.
Table 4 Outcome parameters and technical details

a Fisher's exact test unless indicated otherwise

b Student's $t$-test

\begin{tabular}{llll}
\hline & $\begin{array}{l}\text { Open group } \\
(n=31) \\
n(\%)\end{array}$ & $\begin{array}{l}\text { Laparoscopic group } \\
(n=13) \\
n(\%)\end{array}$ & $p$ Value $^{\mathrm{a}}$ \\
\hline Operative time: min (range) & $150(35-300)$ & $180(90-360)$ & $0.12^{\mathrm{b}}$ \\
Conversion rate & - & $2(15)$ & 0.11 \\
Mesh implantation & $25(81)$ & $13(100)$ & 0.04 \\
Mesh size: $\mathrm{cm}^{2}$ (range) & $500(120-2000)$ & $600(300-1100)$ & $0.80^{\mathrm{b}}$ \\
Hospital stay: days (range) & $7.6(3-14)$ & $7.0(3-20)$ & $0.88^{\mathrm{b}}$ \\
Recurrence rate & $9(35)$ & $2(15)$ & 0.28 \\
Surgical complications & $5(19)$ & $2(15)$ & 0.99 \\
Wound infection & 1 & 1 & \\
Hematoma & 1 & 1 & \\
Ileus & 1 & - & \\
Seroma & 1 & - & \\
Wound dehiscence & 1 & - & \\
\hline
\end{tabular}


Table 5 Incidence, surgical technique, and recurrence rate of incisional hernia after liver transplantation in collected series

\begin{tabular}{|c|c|c|c|c|c|c|c|}
\hline Author & $\begin{array}{l}\text { OLT } \\
(n)\end{array}$ & $\begin{array}{l}\text { Incidence } \\
(\%)\end{array}$ & $\begin{array}{l}\text { Follow-up } \\
\text { (months) }\end{array}$ & $\begin{array}{l}\text { Follow-up } \\
(\%)\end{array}$ & $\begin{array}{l}\text { Hernia } \\
\text { repair }\end{array}$ & $\begin{array}{l}\text { Recurrence } \\
\text { rate }(\%)\end{array}$ & $\begin{array}{l}\text { Follow-up } \\
\text { (months) }\end{array}$ \\
\hline Janssen [2] & 290 & 17.2 & 51 & 100 & Open & 22 & - \\
\hline Vardanian [6] & 959 & 4.6 & - & 100 & Open & 16 & 14 \\
\hline \multirow[t]{2}{*}{ Mekeel [15] } & 365 & 7.6 & - & - & Open & 29 & 51 \\
\hline & & & & & Lap & 7.6 & 14.6 \\
\hline \multirow[t]{2}{*}{ Present series } & 225 & 25.3 & 61 & 95 & Open & 35 & 56 \\
\hline & & & & & Lap & 15 & 29 \\
\hline
\end{tabular}

$O L T$ orthotopic liver transplantation

Disclosures Drs. Anita Kurmann, Guido Beldi, Stephan A. Vorburger, Christian A. Seiler, and Daniel Candinas have no conflicts of interest or financial ties to disclose.

\section{References}

1. Gomez R, Hidalgo M, Marques E, Marin L, Loinaz C, Gonzalez I, Garcia I, Moreno E (2001) Incidence and predisposing factors for incisional hernia in patients with liver transplantation. Hernia 5:172-176

2. Janssen H, Lange R, Erhard J, Malago M, Eigler FW, Broelsch CE (2002) Causative factors, surgical treatment, and outcome of incisional hernia after liver transplantation. Br J Surg 89:10491054

3. Kahn J, Muller H, Iberer F, Kniepeiss D, Duller D, Rehak P, Tscheliessnigg K (2007) Incisional hernia following liver transplantation: incidence and predisposing factors. Clin Transplant 21:423-426

4. Piazzese E, Montalti R, Beltempo P, Bertelli R, Puviani L, Pacile V, Nardo B, Cavallari A (2004) Incidence, predisposing factors, and results of surgical treatment of incisional hernia after orthotopic liver transplantation. Transplant Proc 36:3097-3098

5. Shi LW, Verran D, Rao AR, Stewart GJ, McCaughan GW (2003) Incisional hernia following orthotopic liver transplantation. Transplant Proc 35:425-426

6. Vardanian AJ, Farmer DG, Ghobrial RM, Busuttil RW, Hiatt JR (2006) Incisional hernia after liver transplantation. J Am Coll Surg 203:421-425

7. Beldi G, Ipaktchi R, Wagner M, Gloor B, Candinas D (2006) Laparoscopic ventral hernia repair is safe and cost effective. Surg Endosc 20:92-95
8. Lomanto D, Iyer SG, Shabbir A, Cheah WK (2006) Laparoscopic versus open ventral hernia mesh repair: a prospective study. Surg Endosc 20:1030-1035

9. McGreevy JM, Goodney PP, Birkmeyer CM, Finlayson SR, Laycock WS, Birkmeyer JD (2003) A prospective study comparing the complication rates between laparoscopic and open ventral hernia repairs. Surg Endosc 17:1778-1780

10. Olmi S, Scaini A, Cesana GC, Erba L, Croce E (2007) Laparoscopic versus open incisional hernia repair: an open randomized controlled study. Surg Endosc 21:555-559

11. Toso C, Meeberg GA, Bigam DL, Oberholzer J, Shapiro AM, Gutfreund K, Ma MM, Mason AL, Wong WW, Bain VG, Kneteman NM (2007) De novo sirolimus-based immunosuppression after liver transplantation for hepatocellular carcinoma: long-term outcomes and side effects. Transplantation 83:11621168

12. Langer C, Liersch T, Kley C, Flosman M, Suss M, Siemer A, Becker H (2003) Twenty-five years of experience in incisional hernia surgery: a comparative retrospective study of 432 incisional hernia repairs. Chirurg 74:638-645

13. Sorensen LT, Hemmingsen UB, Kirkeby LT, Kallehave F, Jorgensen LN (2005) Smoking is a risk factor for incisional hernia. Arch Surg 140:119-123

14. Harold K, Mekeel K, Spitler J, Frisella M, Merritt M, Tessier D, Matthews B (2009) Outcomes analysis of laparoscopic ventral hernia repair in transplant patients. Surg Endosc 23:1835-1838

15. Mekeel K, Mulligan D, Reddy KS, Moss A, Harold K (2007) Laparoscopic incisional hernia repair after liver transplantation. Liver Transpl 13:1576-1581

16. Barbaros U, Asoglu O, Seven R, Erbil Y, Dinccag A, Deveci U, Ozarmagan S, Mercan S (2007) The comparison of laparoscopic and open ventral hernia repairs: a prospective randomized study. Hernia 11:51-56 